\title{
OX26/CTX-conjugated PEGylated liposome as a dual-targeting gene delivery system for brain glioma
}

Pei-jian Yue ${ }^{1}$, Lei He${ }^{1}$, Shu-wei Qiu' ${ }^{1}$ Yi Li ${ }^{1}$, Yi-ji Liao ${ }^{3}$, Xiang-pen $\mathrm{Li}^{1}$, Dan Xie ${ }^{3}$ and Ying Peng ${ }^{1} 2^{*}$

\begin{abstract}
Background: The successful gene delivery into the brain is a major challenge due to the presence of the blood-brain barrier (BBB). In order to transport plasmid DNA across the BBB and target the brain glioma, the PEGylated liposomes (PLs) modified with OX26 and chlorotoxin (CTX) were developed as a dual-targeting gene delivery system, and the therapeutic efficacy of OX26/CTX-PL/PC27 against glioma was evaluated using in vitro and in vivo experimental models.

Methods: The PEGylated liposome complexes were prepared by the reverse phase evaporation method, and their physicochemical properties were examined. The transfection efficiency, intracellular distribution, in vitro effects of OX26/CTX-PL/PC27 were determined on C6, F98 and HEK293T cell lines. The dual-targeting therapeutic efficacy of OX26/CTX-PL/pC27 against glioma were assessed using the BMVECs/C6 cells co-culture model and the rat orthotopic glioma model.

Results: The OX26/CTX-PL/pDNA complexes exhibited a subglobose shape, and possessed notably low toxicities to HEK293T and C6 cells post $4 \mathrm{~h}$ incubation. In the in vitro transfection experiment, gene expressions of hTERTC27 from C6 and F98 cells were significantly improved by OX26 and CTX modification. Our in vitro results also showed that OX26 endowed the PLs with the transport ability across the BBB. Using the BMVECs/C6 cells co-culture model, the viability of C6 cells was decreased to 46.0\% after OX26/CTX-PL/pC27 transfection. The OX26/CTX-PL/pC27 complexes exhibited enhanced therapeutic effects on C6 cells. Moreover, the dual-targeting therapeutic effects were further conformed with diminished tumor volumes $\left(18.81 \pm 6.15 \mathrm{~mm}^{3}\right.$ ) and extended median survival time (46 days) in C6 glioma-bearing rats. Immunohistochemical analysis revealed the therapeutic effects derived from enhanced hTERTC27 expression in the tumor site.
\end{abstract}

Conclusions: The PEGylated liposomes modified with OX26 and CTX are able to significantly promote cell transfection, increase the transport of plasmid DNA across the BBB and afterwards target the brain glioma cells in vitro and in vivo, exhibit the most significant therapeutic efficacy. The ligand OX26 plays a critical role in transporting the lipoplexes across the BBB, and CTX acts as a major role in targeting brain glioma cells. The results would encourage further developments for non-invasive targeting therapy of brain gliomas by intravenous injection.

Keywords: Dual-targeting, Gene therapy, Chlorotoxin, Blood-brain barrier, Glioma

\footnotetext{
*Correspondence: docpengy123@163.com

'Department of Neurology, Sun Yat-sen Memorial Hospital, Sun Yat-sen

University, NO.107, Yan Jiang Xi Road of Guangzhou, Guangzhou 510120,

China

${ }^{2}$ Key Laboratory of Malignant Tumor Gene Regulation and Target Therapy of Guangdong Higher Education Institutes, Sun Yat-sen University, Guangzhou

510120, China

Full list of author information is available at the end of the article
}

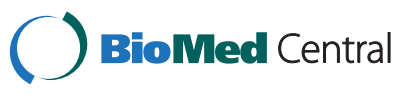

(c) 2014 Yue et al.; licensee BioMed Central Ltd. This is an Open Access article distributed under the terms of the Creative Commons Attribution License (http://creativecommons.org/licenses/by/2.0), which permits unrestricted use, distribution, and reproduction in any medium, provided the original work is properly credited. The Creative Commons Public Domain Dedication waiver (http://creativecommons.org/publicdomain/zero/1.0/) applies to the data made available in this article, unless otherwise stated. 


\section{Background}

Gliomas are the most frequent primary intracranial tumors in adults, and the yearly incidence is six cases per 100000 [1]. The high-grade glioma, glioblastoma multiforme (GBM), almost invariably infiltrates the surrounding normal brain tissue, which makes it impossible for a complete surgical tumor removal, and is typically associated with rapid progression and a fatal outcome [2]. Another obstacle for the treatment of GBM is the presence of the blood-brain barrier (BBB), which prevents nearly all large-molecule drugs and more than $98 \%$ of smallmolecule pharmaceuticals entering the brain tissue [3]. Over the past 3 decades, the standard treatment has evolved to include maximal safe surgical resection, radiation therapy and temozolomide chemotherapy, while the median survival of GBM patients only achieves 14.6 months. GBM remains to be lethal for most of the patients $[4,5]$.

Alternatively, gene therapy may offer a promising cure for various diseases including GBM. To obtain a better therapeutic effect, a gene delivery system is urgent for clinic employ to transport genes across the BBB and then target the brain glioma.

Liposomes, as an effective gene vehicle, are rapidly eliminated from the blood circulation by the mononuclear phagocyte system (MPS) after intravenous administration [6-8]. By conjugating polyethyleneglycol (PEG) to the surface of liposomes, the PEG outer shell can reduce protein opsonization and subsequent phagocytosis by the MPS, resulting in an increased circulation time [9]. This kind of sterically stable, long-circulating liposomes have led to a new era in the liposome drug delivery [10-12]. By coupling with targeting antibodies, peptides, and small molecules, such as OX26 [13], transferring (Tf) [14], angiopep-2 [15] and folate [16], the pegylated liposomes can actively target the tumor sites. Such a targeting gene delivery system is characterized with a high stability of the encapsulated DNA under physiological conditions and a prolonged circulation half life in vivo, and finally exerts greater antitumor activities, compared with the conventional liposomes loaded with therapeutic genes $[8,17,18]$.

The transferrin receptor (TfR) is abundant on the brain capillary endothelium, one component of the BBB, and therefore the TfR monoclonal antibody (mAb) of rats, OX26, is able to bind to an extracellular domain of TfR and transport across the $\mathrm{BBB}$ via the endogenous transferrin transport system $[17,19]$. And since the binding domain of OX26 is distinct from the transferrin binding site, it does not interfere with Tf binding under physiological conditions [20]. Thus, the OX26 is a very efficient targeting antibody candidate in brain drug delivery [21]. However, the TfRs express not only on the $\mathrm{BBB}$ and tumor cells, but also on neuronal plasma membrane as well as other organs, such as liver and spleen. As a result, the expression of exogenous plasmid DNA for this strategy reaches throughout the central nervous system, leading to a lack of the specific targeting to the tumor tissue $[13,17,22]$.

Chlorotoxin (CTX), originally isolated from Leiurus quinquestriatus venom, is a 36-amino acid peptide tightly folded via four disulfide bridges. Several researches have indicated that CTX specifically binds to gliomas and tumors of neuroectodermal origin rather than non-neoplastic cells or normal brain $[23,24]$, and this specific binding to cancer cells is facilitated by matrix metalloproteinase-2 (MMP-2) [25]. These characteristics make this molecule an attractive targeting candidate for the diagnosis and treatment of tumors $[26,27]$.

hTERTC27, a $27 \mathrm{kDa}$ C-terminal polypeptide of human telomerase reverse transcriptase (hTERT), is capable of inducing telomere dysfunctions, anaphase chromosome end-to-end fusions in hTERT-positive HeLa cells, and inhibits HeLa cell growth and tumorigenicity in nude mice xenografts [28]. Especially, hTERTC27 takes effect without perturbing the endogenous telomerase activity, thereby minimizing the potential side effects on telomerase positive reproductive cells and proliferative cells of renewal tissues in anti-telomerase therapies [29,30].

In the present study, we developed a dual-targeting system, plasmid IRES2-EGFP/hTERTC27 (pC27)-loaded PEGylated liposomes (PLs) modified with OX26 and CTX (OX26/CTX-PL/pC27) as a platform for the targeting delivery of $\mathrm{pC} 27$ to glioma. This system is expected to transport $\mathrm{pC} 27$ across the $\mathrm{BBB}$ and then target brain glioma mediated by OX26 and CTX, respectively. The objective of this study is to determine the therapeutic efficacy of OX26/CTX-PL/pC27 in the treatment of glioma.

\section{Results and discussion}

Successful gene delivery into the brain is a major challenge due to the presence of the $\mathrm{BBB}$. Over the last decade, a number of ligands, such as OX26, folate and angiopep-2, have been verified capable of specifically binding to surface receptors on the target sites, resulting in increased selectivity [31,32]. Accordingly, there have been great developments concerning the brain drug delivery systems $[14,33,34]$. However, most of them are developed for delivering daunorubicin, paclitaxel, or other widely used chemotherapeutics in glioma therapy. In the present study, we employed the PEGylated liposomes as the delivery vector of plasmid DNA and constructed the dual-targeting gene delivery system.

OX26-PL/pDNA, OX26/CTX-PL/pDNA complexes were prepared through the outer maleimide groups of PLs specifically reacting with the thiol groups of OX26-SH and CTX$\mathrm{SH}$ (Figure 1). To explore the effects of the ratios of DC-chol to pDNA on the particle size and zeta potential, we prepared PL/pDNA complexes with different weight ratios under the condition of fixing the amount 


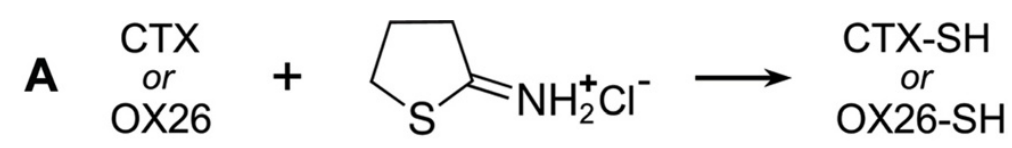

Traut's Reagent
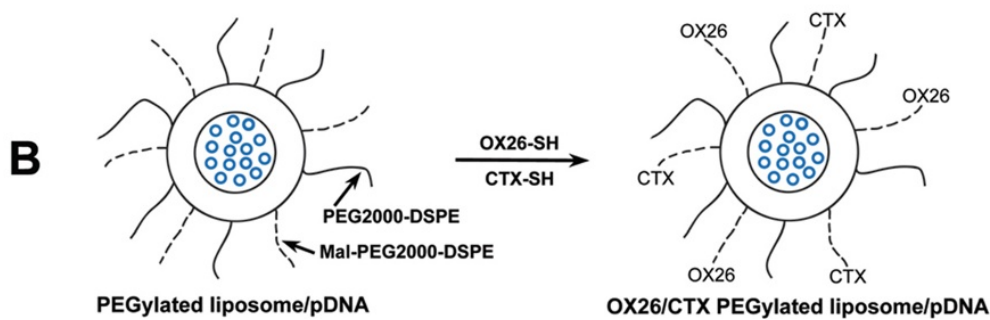

Figure 1 The schematic diagram for the synthesis of targeting PL/pDNA complexes. (A) The OX26 and CTX were thiolated by 2-iminothiolane (Traut's reagent) at room temperature for 1 hour. (B) The outer maleimide groups of PL/pDNA react with the thiolated OX26 and CTX to form targeting PL/pDNA complexes.

of S100-PC and pDNA. As the weight ratio of DCchol/pDNA reached $6: 1$, the particle size tended to be stable (Additional file 1: Figure S1).

The mean particle size of all PL/pDNA complexes was approximately $120 \mathrm{~nm}$, with an appropriate polydispersity index (PDI, approximately 0.2 ). All of the charge values were positive, and this guaranteed high pDNA encapsulation efficiency by electrostatic attraction of opposite charges (Additional file 2: Table S1). The PL/ pDNA complexes exhibited subglobose shape of moderate uniform particle size and there was no aggregation phenomenon of the particles. The particle size measured from the TEM images was in good agreement with that measured by the laser scattering method (Additional file 3: Figure S2). No significant change in the mean particle size of the liposome complexes was detectable after 1 week when kept in PBS at $4^{\circ} \mathrm{C}$. In DMEM containing $10 \% \mathrm{FBS}$, the liposome complexes remained stable in terms of size for $8 \mathrm{~h}$ at $37^{\circ} \mathrm{C}$ (data not shown).

The size of particles plays a critical role in their clearance by the spleen. Since the interendothelial cell slit (IES) size of the spleen rarely exceeds 200 to $500 \mathrm{~nm}$ in width, particles must be either small or deformable enough to avoid the splenic filtration through the IES of venous sinuses. Therefore ideally, the size of particles should not exceed $200 \mathrm{~nm}[35,36]$. Besides, it has been reported that the nanoparticles with a mean diameter approximately $100 \mathrm{~nm}$ showed prolonged blood circulation and a relatively low rate of MPS uptake [37]. The mean diameter of the different $\mathrm{PL} / \mathrm{pDNA}$ complexes in this study was approximately $120 \mathrm{~nm}$, which satisfied the size requirements described above. The prolonged blood circulation attributed to make more nanoparticles reach the brain and achieved enhanced permeability and retention (EPR) effects.

Positively charged particles can fully condense and coat DNA, thus avoiding the degradation of DNases
[38]. However, such particles tend to form small aggregates in the presence of the negatively charged serum proteins once i.v. administered and often exhibit a rapid blood clearance phase with a large dose accumulating in the lung and the liver. Grafting neutral PEG onto the surface of the cationic liposomes prevents aggregation and increases their stability due to the charge shielding [39].

The encapsulation efficiency of all lipoplexes was show in Additional file 4: Table S2. Compared with PL/pEGFP or $\mathrm{PL} / \mathrm{pC} 27$, the encapsulation efficiency of OX26-PL/ pDNA, OX26/CTX-PL/pDNA decreased to some extent. It may be a consequence of pDNA releasing from complexes during the reaction between OX26, CTX and PL/ pDNA. The coupling efficiencies of OX26 in OX26-PL/ $\mathrm{pC} 27, \mathrm{OX} 26 / \mathrm{CTX}-\mathrm{PL} / \mathrm{pC} 27$ were $40.4 \pm 5.1 \%$ and $35.4 \pm$ $3.8 \%$, respectively. The coupling efficiencies of CTX in CTX-PL/pC27, OX26/CTX-PL/pC27 were $44.9 \pm 6.1 \%$ and $42.5 \pm 5.5 \%$, respectively. There was no obvious interaction between OX26 and CTX during the coupling reaction.

The cytotoxicity of the PL/pEGFP, OX26-PL/pEGFP and OX26/CTX-PL/pEGFP complex at a series of plasmid weights were evaluated with CCK-8 Kits in HEK293T and C6 cells (Additional file 5: Figure S3). Cell viability decreased as the weight of pEGFP in the complex increased. For HEK293T, cell viability of OX26/CTX-PL/pEGFP group was $94.05 \% \pm 0.43 \%$ and $82.94 \% \pm 0.41 \%$ at $0.1 \mu \mathrm{g}$ and $1.6 \mu \mathrm{g}$ pEGFP, respectively. For C6, cell viability was $93.67 \% \pm 0.47 \%$ and $81.89 \% \pm 0.44 \%$ at $0.1 \mu \mathrm{g}$ and $1.6 \mu \mathrm{g}$ pEGFP, respectively. The PL complexes showed notably low toxicity to the HEK293T and C6 cells after $4 \mathrm{~h}$ incubation, which might be attributed to the similarity of the liposomes to the cell membranes and the charge-shielding effects of PEG chains. No statistical differences in the cell viability were found among PL/pEGFP, OX26-PL/pEGFP and OX26/CTX-PL/pEGFP at the corresponding plasmid 
weights except OX26/CTX-PL/pEGFP at $1.6 \mu \mathrm{g}$ pEGFP ( $p<0.01$ compared with that of PL/pEGFP and OX26-PL/ pEGFP, respectively).

The transfection efficiency of complexes was visualized by observation of EGFP positive cells using a fluorescence microscope. For HEK 293 T cells, no obvious differences of the fluorescent density were observed among PL/pEGFP, OX26-PL/pEGFP and OX26/CTX-PL/pEGFP containing $1 \mu \mathrm{g}$ pEGFP. For C6 and F98 cells, the highest transfection efficiency was found in OX26/CTX-PL/ pEGFP complex while the weakest fluorescent density was displayed in PL/pEGFP complex at $1 \mu \mathrm{g}$ pEGFP (Additional file 6: Figure S4). The transfection efficiency was further quantified by the flow cytometry assay. When HEK293T cells were transfected with Lipo2000/ pEGFP, PL/pEGFP, OX26-PL/pEGFP and OX26/CTX$\mathrm{PL} / \mathrm{pEGFP}$ complexes at $1 \mu \mathrm{g}$ pEGFP, the average ratios of EGFP-positive cells were $84.2 \%, 44.3 \%, 43.2 \%$ and $44.3 \%$, respectively (Figure 2A). However, the average ratios were $35.2 \%, 20.6 \%, 27.4 \%$ and $31.2 \%$ for C6 cells, and $42.6 \%, 24.3 \%, 31.3 \%$ and $36.1 \%$ for F98 cells, respectively (Figure 2B, 2C). No significance on transfection efficiency was shown in HEK 293 T cells ( $p>0.05$ ), while compared with that of PL/pEGFP for C6 and F98 cells, higher transfection efficiencies of OX26-PL/pEGFP and OX26/CTX-PL/pEGFP were indicated $(\mathrm{p}<0.01)$ (Figure 2). This was probably attributed to the absence of the corresponding receptors of OX26 or CTX on HEK293T cells, and the recognition of OX26 to TfR, CTX to MMP-2 in C6 and F98 cells (both TfR and MMP-2 are over expressed in the rat glioma cells).

To quantify the transgene expression level, luciferase reporter assays were carried out. As the increase of the weight of pGL3-luc, enhanced luciferase activities were shown among Lipo2000/pGL3-luc, PL/pGL3-luc, OX26PL/pGL3-luc and OX26/CTX-PL/pGL3-luc. For C6 and F98 cells, OX26-PL/pGL3-luc and OX26/CTX-PL/pGL3luc complexes obtained obvious higher luciferase activities than the PL/pGL3-luc complexes among all the tested weights of pGL3-luc, and there was also obvious difference between OX26-PL/pGL3-luc and OX26/CTX-PL/ pGL3-luc (Additional file 7: Figure S5B, C), indicating that the novel OX26/CTX-PL/pGL3-luc complexes increased the transgene expression due to its targeting ligands. No differences were found in luciferase activities among the three complexes above in HEK293T cells $(p>0.05)$ (Additional file 7: Figure S5A). Consistent with results from the flow cytometry assay, this further proved the possible targeting effect of OX26 and CTX.

Intracellular expression and distribution of hTERTC27 was observed by virtue of confocal microscope (Additional file 8: Figure S6). The expression of hTERTC27 presented in a time-dependent manner. With extension of culture time, positive cells and fluorescence intensity of gene
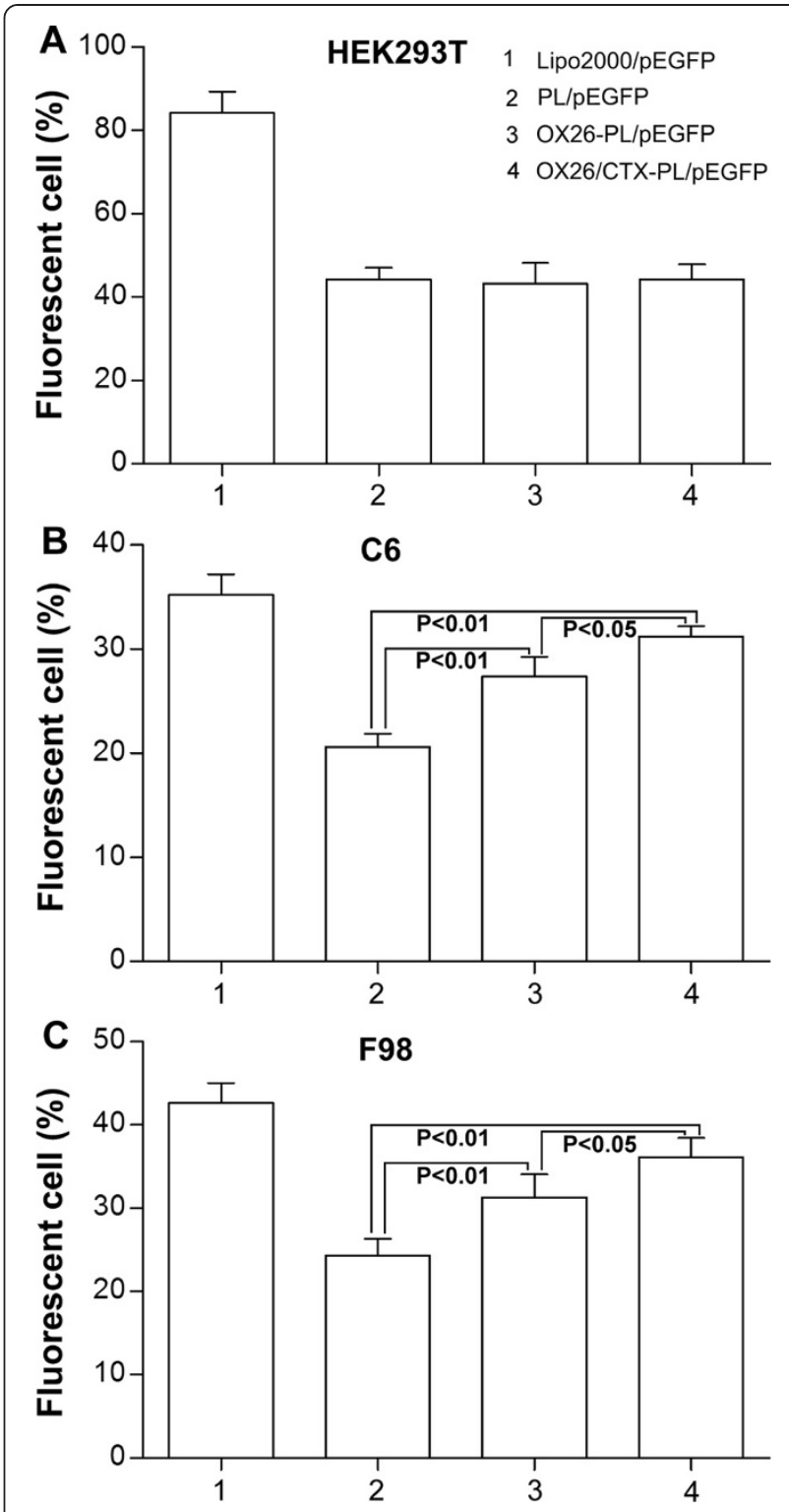

Figure 2 Transfection efficiency of Lipo2000/pEGFP, PL/pEGFP, OX26-PL/pEGFP and OX26/CTX-PL/pEGFP complexes containing $1 \mu \mathrm{g}$ pIRES2-EGFP by FACS analysis in (A) HEK293T cells, (B) C6 glioma cells, (C) F98 glioma cells. Data are expressed as mean \pm SD $(n=3)$.

expression increased. The hTERTC27 protein distributed throughout the C6 cells, though primarily within the cell nuclei.

To explore the potential therapeutical effect of OX26/ CTX-PL/pC27 complex, its cytotoxicity was initially evaluated at a series of plasmid concentrations in C6 glioma cells by CCK- 8 assay. As shown in Figure 3A, reduction of cell viability was shown with the increase of weight of pIRES2-hTERTC27 in the complex. Figure 3B showed the viability of $\mathrm{C} 6$ glioma cells 

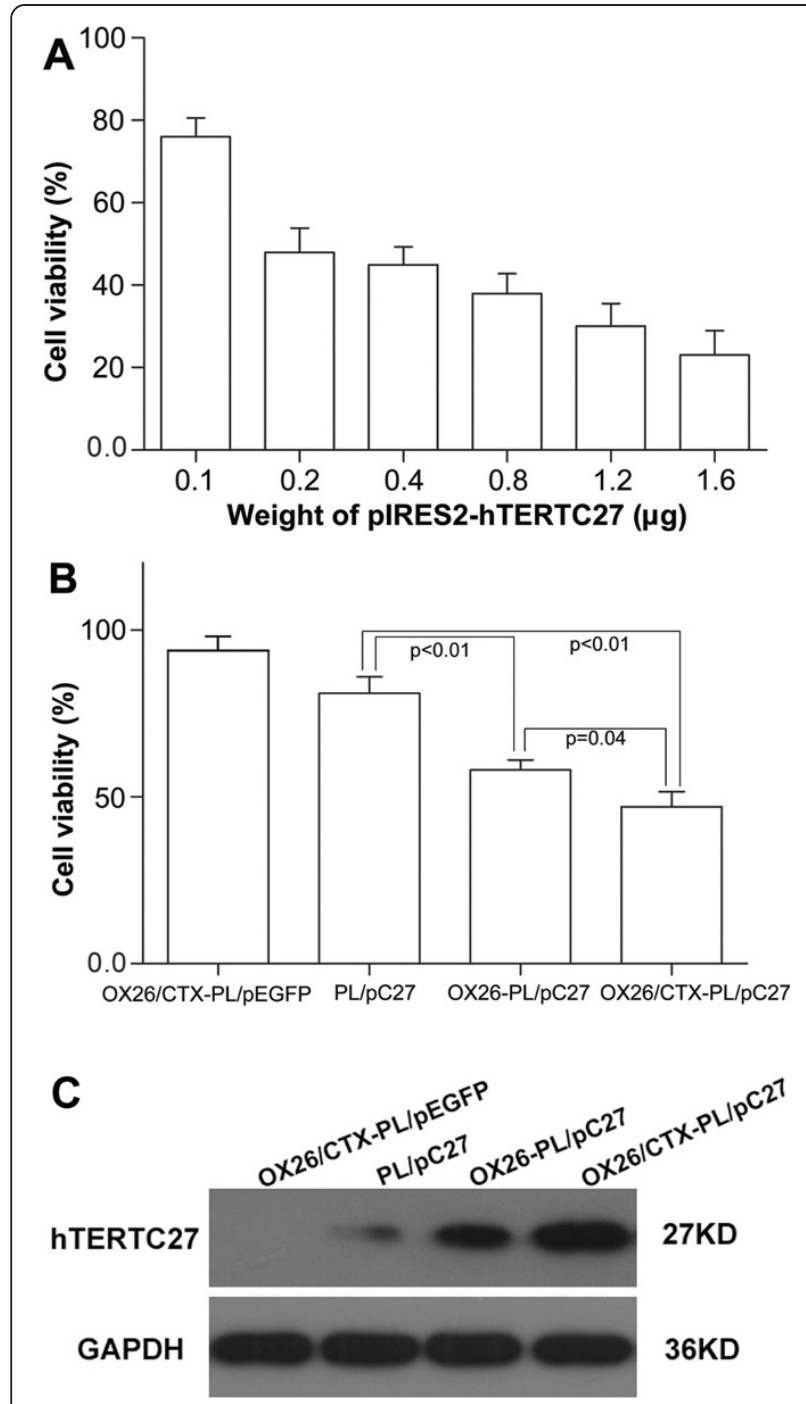

Figure 3 The therapeutical effect of OX26/CTX-PL/pC27 complex and western blot analysis. (A) The cell viability of the C6 glioma cells after transfection of OX26/CTX-PL/pC27 complex at a series of plasmid weights. (B) The viability of C6 glioma cells after transfection of OX26/CTX-PL/pEGFP, PL/pC27, OX26-PL/pC27 and OX26/CTX-PL/pC27 at $0.2 \mu \mathrm{g}$ pDNA. (C) Western blot analysis of the expression of hTERTC27 in C6 glioma cells after transfections of OX26/CTX-PL/pEGFP, PL/pC27, OX26-PL/pC27 and OX26/CTX-PL/ pC27complexes at $4 \mu \mathrm{g}$ pDNA. OX26/CTX-PL/pEGFP was set as the negative control.

treated with PL/pC27, OX26-PL/pC27 and OX26/CTX$\mathrm{PL} / \mathrm{pC} 27$ at $0.2 \mu \mathrm{g} \mathrm{pC} 27(81 \% \pm 5 \%, 58 \% \pm 3 \%$ and $47 \% \pm$ $4.5 \%$, respectively). Obviously, OX26-PL/pC27 and OX26/ CTX-PL/pC27 exhibited higher toxicity to C6 glioma cells than $\mathrm{PL} / \mathrm{pC} 27$, and there was also obvious difference between OX26-PL/pC27 and OX26/CTX-PL/pC27 ( $\mathrm{p}=0.04)$. The results indicated that the strength of antitumor effects was OX26/CTX-PL/pC27 > OX26-PL/pC27 > PL/ $\mathrm{pC} 27$. The results may be explained by the higher
hTERTC27 protein level in the OX26/CTX-PL/pC27 and OX26-PL/pC27 treatment groups (Figure 3C). Therefore, we concluded that targeting ligands OX26 and CTX promoted cell transfection of lipoplexes, increased hTERTC27 protein expression, and enhanced the therapeutical effect on C6 cells.

In vitro $\mathrm{BBB}$ model was established and confirmed by the permeation experiment and transendothelial electrical resistance (TEER) values $\left(>250 \Omega \mathrm{cm}^{2}\right)$. No obvious reduction of TEER values was observed during the experiment, indicating that transport of $\mathrm{pC} 27$ did not disrupt the $\mathrm{BBB}$ barrier. Figure $4 \mathrm{~A}$ showed the transport ability of different lipoplexes across BBB model at the same concentration of pDNA. The transport ratios were $3.23 \%$ for $\mathrm{PL} / \mathrm{pC} 27,6.50 \%$ for OX26-PL/pC27, $6.42 \%$ for OX26/CTX-PL/pC27, 3.08\% for PL/pC27 preconditioned with OX26, 3.00\% for OX26-PL/pC27 preconditioned with OX26, 3.13\% for OX26/CTX-PL/pC27 preconditioned with $\mathrm{OX} 26$ at $4 \mathrm{~h}$, respectively. When the model was pre-incubated with free OX26 to saturate the TfR on the BBB, the transport ratios of OX26-PL/ pC27 and OX26/CTX-PL/pC27 decreased significantly, which displayed no difference with that of $\mathrm{PL} / \mathrm{pC} 27$. There was no obvious alternation for $\mathrm{PL} / \mathrm{pC} 27$ preconditioned with and without OX26. The results revealed OX26 modification on the PL/pDNA complexes played a critical role in the transport assay while CTX did not exert effect on the transport across BBB, and the increased transport ability of the PL modified with OX26 may be mediated by TfR. Our results were supported with the research that the TF-conjugated liposomes were able to increase the delivery of drug across the BBB mediated by TfR [40].

To evaluate the dual-targeting effects in vitro, the toxicity test of the lipoplexes on C6 glioma cells after crossing the $\mathrm{BBB}$ was conducted with the BBB/C6 co-culture model. As shown in Figure 4B, the viability of C6 cells were $89.9 \%$ for $\mathrm{PL} / \mathrm{pC} 27,59.7 \%$ for OX26-PL/pC27, 46.0\% for OX26/CTX-PL/pC27, 88.1\% for PL/pC27 preconditioned with OX26, 79.0\% for OX26-PL/pC27 preconditioned with OX26, 74.1\% for OX26/CTX-PL/pC27 preconditioned with OX26, respectively. The OX26/ CTX-PL/pC27 complexes exhibited enhanced cytotoxicity. Furthermore, after pre-incubation with OX26, the cytotoxicity of OX26/CTX-PL/pC27 was notably reduced and no differences were displayed, compared with that of $\mathrm{PL} / \mathrm{pC} 27$, and $\mathrm{OX} 26-\mathrm{PL} / \mathrm{pC} 27$ ( $\mathrm{p}>0.05$ ). The results indicated evident dual-targeting effects of OX26/ CTX-PL/pC27 due to the elevated endocytosis mediated by the specific binding CTX to MMP-2, following the increased transport across the $\mathrm{BBB}$ by the specific binding OX26 to TfR.

The rat C6 glioma models were employed in our study for further verifying the dual-targeting treatment effect of OX26/CTX-PL/pC27 in vivo (Figure 5A F). The average 

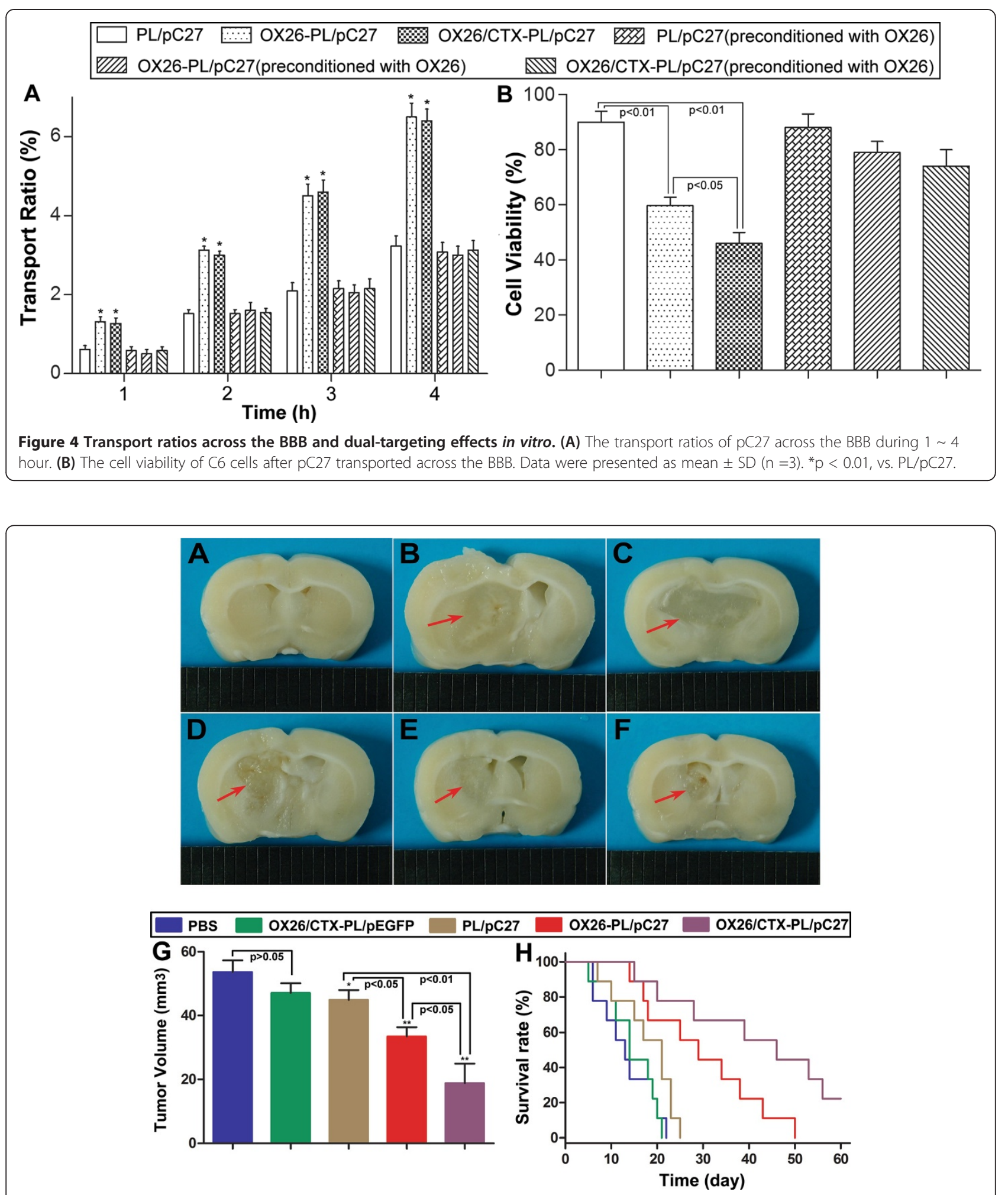

Figure 5 Dual-targeting effects of OX26/CTX-PL/pC27 complex and survival monitoring in vivo. (A) (F): the cross-sections of the rat brain among different treatment groups. (A) sham-operated group (without C6 cells or drug administration); (B) PBS control group; (C) OX26/CTX-PL/ pEGFP control group; (D) PL/pC27 group; (E) OX26-PL/pC27 groups; (F) OX26/CTX-PL/pC27 group. The red arrows designated the tumor sites. (G) The tumor volumes of the C6 glioma bearing rats among different treatment groups. Data were presented as mean \pm SD $(n=6) .{ }^{*} p>0.05,{ }^{* *} p<0.01$, vs. OX26/CTX-PL/pEGFP. (H) The Kaplan-Meier survival curves of C6 glioma bearing rats treated with PBS, OX26/ CTX-PL/PEGFP, PL/PC27, OX26-PL/PC27 and OX26/CTX-PL/pC27complexes after inoculation, respectively. 
tumor volumes on day 18 were $53.61 \pm 3.71 \mathrm{~mm}^{3}$ for PBS group, $47.1 \pm 3.02 \mathrm{~mm}^{3}$ for OX26/CTX-PL/pEGFP group, $44.87 \pm 3.12 \mathrm{~mm}^{3}$ for PL/C27 group, $33.49 \pm 2.83 \mathrm{~mm}^{3}$ for OX26-PL/pC27 group and $18.81 \pm 6.15 \mathrm{~mm}^{3}$ for OX26/ CTX-PL/pC27 group, respectively. As shown in Figure 5G, the OX26/CTX-PL/pC27 therapy significantly diminished the tumor size when compared with the controls $(\mathrm{p}<0.01)$, $\mathrm{PL} / \mathrm{pC} 27(\mathrm{p}<0.01)$ and OX26-PL/pC27 therapy $(\mathrm{p}<0.05)$. On the contrary, OX26/CTX-PL/pEGFP did not exhibit inhibitory effects on the tumor, compared with the PBS control $(\mathrm{p}>0.05)$. Treatment effects of different PL complexes were also reflected by the Kaplan-Meier survival curves (Figure $5 \mathrm{H}$ ). The median survival time of rats treated with OX26/CTX-PL/pC27complexes (46 days) was significantly longer than that of rats treated with PBS (13 days, $\mathrm{p}=0.000)$, OX26/CTX-PL/pEGFP (14 days, $\mathrm{p}=0.000), \mathrm{PL} / \mathrm{pC} 27$ (21 days, $\mathrm{p}=0.002$ ) and OX26-PL/ $\mathrm{pC} 27$ (29 days, $\mathrm{p}=0.038$ ), respectively. These results indicated that OX26-PL/pC27 was able to improve the treatment efficacy while the dual-targeting OX26/CTX-PL/ $\mathrm{pC} 27$ led to the most significant tumor inhibition and the most significant improvement in the median survival time of tumor-bearing rats. These findings offered the robust evidence for the dual-targeting therapeutic effects.

To observe the histopathological changes and confirm the expression of the hTERTC27 protein, HE staining and IHC analysis were conducted. The hTERTC27 histochemistry showed that the gene was expressed only in the tumor site by EPR effects in the PL/pC27 group (Additional file 9: Figure S7B), and widely expressed throughout the brain in the OX26-PL/pC27 group (Additional file 9: Figure S7C). However, compared with that of the OX26-PL/pC27 group, the hTERTC27 protein mainly occurred in the tumor site and there was marked reduction in the expression out of the tumor site in the OX26/CTX-PL/pC27 group (Additional file 9: Figure S7D). As shown in Figure $6\left(\mathrm{~A}_{1} \sim \mathrm{F}_{1}\right)$, all glioma tissues were hypercellular with abundant cytoplasm, nuclear pleomorphism and partly with large nucleolus. In the OX26-PL/pC27 group, vacuolization was observed in most of the tumor cells and small, scattered necrosis happened sometimes (Figure $6 \mathrm{E}_{1}$ ). However, apoptotic bodies, nuclear fragments and massive necrosis occurred on the basis of the vacuolization in the OX26/ CTX-PL/pC27 group (Figure $6 \mathrm{~F}_{1}$ ). Further IHC study was performed to observe the expression of the hTERTC27 protein in the tumor cells and normal cells adjacent to cancer. The nuclei were stained blue and no hTERTC27 distributed in the tumor cells both in the PBScontrol and OX26/CTX-PL/pEGFP groups (Figure $6 \mathrm{~B}_{2}$, $\mathrm{C}_{2}$ ). In the PL/pC27, OX26-PL/pC27 and OX26/CTX-PL/ pC27 groups, immunostaining of hTERTC27 protein was visualized throughout the cell, though primarily in the cell nuclei of glioma, and the scores were $1.33 \pm 0.58,7.33 \pm 1.16$ and $11.00 \pm 1.73$ in tumor cells while the scores were 0 , $3.33 \pm 1.15$ and $8.00 \pm 1.73$ in normal cells, respectively (Figure $6 \mathrm{D}_{2} \sim \mathrm{F}_{3}$ ). The staining score of tumor cells in the OX26/CTX-PL/pC27 group was significantly higher than that in $\mathrm{PL} / \mathrm{pC} 27(\mathrm{p}<0.01)$ and OX26-PL/pC27groups $(\mathrm{p}=0.034)$. On the contrary, the normal cells scored in the OX26/CTX-PL/pC27 group much lower than in the OX26-PL/pC27group ( $<0.01)$, which was consistent with the result of hTERTC27 gross distribution in rat brains. Immunohistochemical analysis further revealed the therapeutic effects derived from hTERTC27 expression in the tumor site.

In a word, compared with the existing studies, our dual-targeting delivery system was designed with the following features: (1) this system was of low toxicity and good biocompatibility; (2) the dual-targeting delivery increased therapeutic gene expression in the tumor site and improved the drug utilization; (3) intravenous administration avoided the damage caused by local injection and conformed to the development direction of nanocarriers; (4) the PEGylated liposomes, dual-targeting delivery, gene therapy and intravenous administration were fused together, and achieved a new breakthrough for the treatment of the glioma.

\section{Conclusions}

The PEGylated liposomes modified with OX26 and CTX are able to significantly promote cell transfection, increase the transport of plasmid DNA across the BBB and afterwards target the brain glioma cells in vitro and in vivo, exhibit the most significant cytotoxicity in vitro and therapeutic efficacy in brain glioma-bearing rats. The ligand OX26 plays a critical role in transporting the lipoplexes across the $\mathrm{BBB}$, and CTX acts as a major role in targeting brain glioma cells. Furthermore, OX26 also contributes to the glioma-targeting effect of the lipoplexes. The results would encourage further developments for non-invasive targeting therapy of brain gliomas by intravenous injection.

\section{Materials and methods Materials}

Soybean phosphatidylcholine (S100-PC) was purchased from Lipoid GmbH (Ludwigshafen, Germany). DC-chol, 2-Iminothiolane hydrochloride (2-IT, Traut's reagent), CTX and sulforhodamine B (SRB) were provided by Sigma-Aldrich (Saint Louis, MO, USA). Mal-PEG2000DSPE was obtained from Avanti Polar Lipids (Alabaster, AL, USA). Anti-Transferrin Receptor antibody (OX-26) and anti-Telomerase reverse transcriptase antibody were purchased from Abcam (Cambridge, UK). Sephadex G-50 and Sepharose CL-4B were provided by Science and Technology Development Co., Ltd. (Beijing, China). Centriprep10 concentrators were purchased from Millipore Amicon (Bedford, MA, USA). NanoOrange ${ }^{\oplus}$ Protein Quantitation 

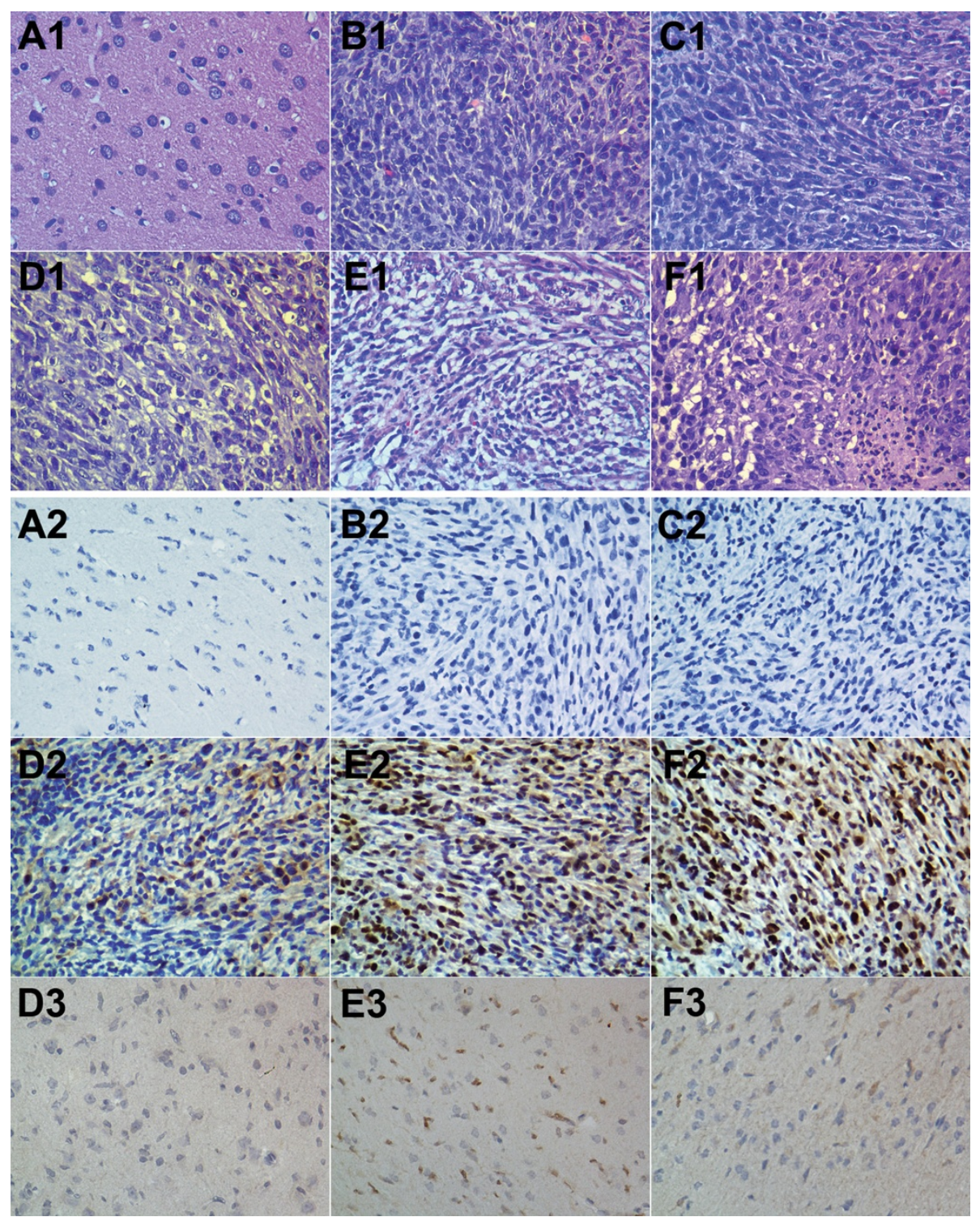

Figure $6 \mathrm{HE}$ staining $\left(A_{1} \sim F_{1}\right)$ and immunohistochemistry $\left(A_{2} \sim F_{3}\right)$ of brain tissues from the $C 6$ glioma bearing rats $(\times 400)$. $A\left(A_{1}, A_{2}\right)$ Normal brain; $\mathbf{B}\left(\mathbf{B}_{1}, \mathbf{B}_{2}\right)$ : PBS-control; $\mathbf{C}\left(\mathbf{C}_{1}, \mathbf{C}_{2}\right)$ : OX26/CTX-PL/pEGFP group; $\mathbf{D}\left(\mathbf{D}_{1}, \mathbf{D}_{2}, \mathbf{D}_{3}\right)$ : PL/pC27 group; $\mathbf{E}\left(\mathbf{E}_{1}, \mathbf{E}_{2}, \mathbf{E}_{3}\right)$ : OX26-PL/pC27 group; $\mathbf{F}\left(\mathbf{F}_{\mathbf{1}}, \mathbf{F}_{\mathbf{2}}, \mathbf{F}_{\mathbf{3}}\right)$ : OX26/CTX-PL/pC27 group. $\mathbf{D}_{\mathbf{2}}, \mathbf{E}_{\mathbf{2}}, \mathbf{F}_{\mathbf{2}}$ were from tumor cells; $\mathbf{D}_{\mathbf{3}}, \mathbf{E}_{\mathbf{3}}, \mathbf{F}_{\mathbf{3}}$ were from normal cells adjacent to cancer.

Kit was purchased from Invitrogen (California, USA). YOYO-1 and LysoTracker Red were purchased from Molecular Probes (Eugene, OR, USA). pIRES2-EGFP (pEGFP) and pIRES2-EGFP/hTERTC27 (pC27) were purified using a E.Z.N.A.TM Fastfilter Plasmid Maxi Kit (Omega, Norcross, GA, USA). Cell Counting Kit-8 (CCK-8) was purchased from Dojindo Molecular Technologies (Tokyo, Japan). Lipofectamine ${ }^{\text {TM }} 2000$ Reagent (Lipo2000) was purchased from Invitrogen (California, USA). pGL3 Luciferase Reporter Vectors (pGL3-luc) and Luciferase Reporter Assay Kit were purchased from Promega (Madison, WI, USA).

\section{Cell culture}

The C6, F98 glioma cells and human embryonic kidney 293 T (HEK $293 \mathrm{~T}$ ) cells were obtained from ATCC (American Type Culture Collection, VA, USA) and were cultured in high glucose Dulbecco's modified Eagle's medium (DMEM, Gibco) supplemented with 10\% fetal bovine serum (FBS, Gibco), $100 \mathrm{U} / \mathrm{ml}$ penicillin and $100 \mu \mathrm{g} / \mathrm{ml}$ streptomycin at $37^{\circ} \mathrm{C}$ in a humidified $5 \% \mathrm{CO} 2$ incubator. Brain microvascular endothelial cells (BMVECs), were isolated from bovine brain and cultured in endothelial cell culture medium (DMEM, 20\% FBS, $100 \mathrm{U} / \mathrm{ml}$ penicillin, $100 \mu \mathrm{g} / \mathrm{ml}$ streptomycin, $2 \mathrm{mmol} / \mathrm{L} \mathrm{L}$-glutamine, 
$100 \mu \mathrm{g} / \mathrm{mL}$ endothelial cell growth factor (ECGF), $20 \mu \mathrm{g} / \mathrm{mL}$ heparin, and $40 \mu \mathrm{U} / \mathrm{mL}$ insulin) [41].

\section{Animals}

Male Wistar rats (250-280 g) were supplied by Laboratory Animal Center of Sun Yat-sen University (Guangzhou, China) and were housed in air-conditioned rooms (temperature: $21 \pm 2^{\circ} \mathrm{C}$; humidity: $55 \pm 4 \%$ and light: $12 \mathrm{~h}$ light/dark cycle). All animal experiments were carried out with the approval of the Ethics Committee of Sun Yat-sen University.

\section{Preparation and characterization \\ Pegylated liposomes (PLs) synthesis and plasmid DNA encapsulation}

PLs were prepared by reverse phase evaporation method as described previously [42,43]. Briefly, $25.1 \mathrm{mg} \mathrm{S100-PC,}$ $19.9 \mathrm{mg}$ DC-chol, $10.5 \mathrm{mg}$ DSPE-PEG, $8.8 \mathrm{mg}$ MalPEG2000-DSPE were dissolved in chloroform. The solution was then evaporated using rotary evaporation to form thin lipid film at room temperature. The dried lipid film was subsequently re-dissolved in chloroform and $0.5 \mathrm{mg}$ plasmid of pEGFP or pC27 in $1 \mathrm{~mL}$ PBS was added. After vortex and ultrasonication at $10^{\circ} \mathrm{C}$ for $5 \mathrm{~min}$, respectively, the solution was evaporated at $30^{\circ} \mathrm{C}$ to form a transparent and opalescence aqueous phase. The aqueous phase was extruded by turns through a $400 \mathrm{~nm}, 200 \mathrm{~nm}$ and $100 \mathrm{~nm}$ polycarbonate filter for 4 times, and the unmodified $\mathrm{PL} / \mathrm{pEGFP}$ and PL/pC27 were formed. The encapsulation efficiency was determined as described previously [44].

\section{Preparation of OX26 and/or CTX-conjugated liposome complexes}

The OX26 and CTX were thiolated by using a 40:1 molar excess of 2-iminothiolane (Traut's reagent) at room temperature for 1 hour, as described previously [6]. The thiolated OX26 and CTX (OX26-SH and CTX$\mathrm{SH}$ ) were incubated with PL/pEGFP and PL/pC27 (the weight ratio of peptide to phospholipid was 1:20) overnight at room temperature [45]. The targeting liposome complexes were separated using a Sepharose CL-4B column and eluted with 0.001 M PBS buffer ( $\mathrm{PH}$ 7.4) from the reaction mixture [46]. The amount of uncoupled OX26 or CTX was determined according to the NanoOrange ${ }^{\oplus}$ Protein Quantitation Kit (Invitrogen Corporation, USA) [47]. The total and uncoupled amounts of OX26 or CTX were signed $C_{0}$ and $C_{1}$, respectively, coupling efficiency $(\mathrm{CE})$ was calculated by the formula: $\mathrm{CE}=\left(1-\mathrm{C}_{1} /\right.$ $\left.\mathrm{C}_{0}\right) \times 100 \%$.

\section{Particle size distribution, zeta potential and stability of liposome complexes}

After the liposome complexes were dispersed in deionized water to make the solution with the final concentration of
$0.25 \mathrm{mg} / \mathrm{mL}$, the particle size distribution and zeta potential were determined by the light scattering method using a Zeta Potential/Particle Size analyzer (Zetasizer Nano ZS90, Malvern, UK) with a scattering angle of $90^{\circ}$ at $25^{\circ} \mathrm{C}$ [48]. The morphology of the liposome complexes were observed using transmission electron microscopy (TEM) (JEM-2010, JEOL, Japan).

In order to determine the size stability of the liposome complexes, the samples $(10 \mathrm{mg} / \mathrm{ml})$ were kept in PBS $(\mathrm{pH} 7.4)(1: 10, \mathrm{v} / \mathrm{v})$ at $4^{\circ} \mathrm{C}$ for 1 week, and then the size change was determined by the analyzer above [49]. In addition, $100 \mu \mathrm{l}$ samples $(10 \mathrm{mg} / \mathrm{ml})$ were added to $1 \mathrm{ml}$ culture medium containing 10\% FBS, and incubated at $37^{\circ} \mathrm{C}$ for $8 \mathrm{~h}$. At $1 \mathrm{~h}, 4 \mathrm{~h}$ and $8 \mathrm{~h}$, the particle size was measured to evaluate the variations in size [36].

\section{In vitro cytotoxicity assay of the modified and unmodified PL/pEGFP complexes}

The cytotoxicity of the PL/pEGFP, OX26-PL/pEGFP and OX26/CTX-PL/pEGFP complexes was measured by CCK8 assay. C6, HEK293T cells were seeded in a 96-well culture plates (Corning-Coaster, Tokyo, Japan) at 7000 cells per well in $100 \mu \mathrm{l}$ DMEM medium for $24 \mathrm{~h}$ to achieve about $70 \%$ confluence. The medium was then replaced with $200 \mu$ solution of different liposome complexes, which were loaded with a series of weights of pEGFP $(0.1 \mu \mathrm{g}, 0.2 \mu \mathrm{g}, 0.4 \mu \mathrm{g}, 0.8 \mu \mathrm{g}, 1.2 \mu \mathrm{g}, 1.6 \mu \mathrm{g})$, for $4 \mathrm{~h}$. Then, cytotoxicity was performed using CCK- 8 Kit. Cells without treatment were used as control. Absorbance was measured at $450 \mathrm{~nm}$ and corrected at $630 \mathrm{~nm}$ by dual wave length detection with TECAN Infinite M200 microplate reader (Tecan, Durham, USA). Cell viability of each group was expressed as a percentage relative to that of control.

\section{In vitro transfection experiment}

C6, F98 and HEK293T cells were incubated in 24-well plates for $24 \mathrm{~h}$ to reach about $70 \%$ confluence. Before transfection, the medium was removed and the cells were washed 2 times with PBS. The cells were incubated with PL/pEGFP, OX26-PL/pEGFP and OX26/CTX-PL/ pEGFP solutions containing $0.5 \mu \mathrm{g}, 1 \mu \mathrm{g}, 2 \mu \mathrm{g}$ pEGFP in serum-free DMEM medium for $4 \mathrm{~h}$ at $37^{\circ} \mathrm{C}$. After exchanging with complete medium, the cells were further incubated $48 \mathrm{~h}$. The positive controls were treated with Lipo2000/pEGFP solutions containing the corresponding amounts of pEGFP while the negative one incubated with PBS only. The fluorescent images were observed and captured by the Eclipse TE2000-U fluorescence microscope (Nikon, Tokyo, Japan). For transfection efficiency analysis, the cells were trypsinized, washed and resuspended in $1.5 \mathrm{ml}$ PBS. Transfection efficiency was evaluated by scoring the percentage of cells expressing green fluorescence protein (EGFP) using a FACS AriaTM System (Becton-Dickinson, San Joes, CA). The 
experiments were performed in triplicates and 15,000 cells were counted in each experiment.

\section{Luciferase reporter assay}

Cells were transfected with the complexes containing $0.5 \mu \mathrm{g}, 1 \mu \mathrm{g}, 2 \mu \mathrm{g}$ pGL3-luc in the 24-well plates in triplicate as described above. After $48 \mathrm{~h}$ of incubation, the cells were lysed by $100 \mu$ lysis buffer for each well. The gene expression level in the lysates was evaluated using a luciferase reporter assay kit with a luminometer (Lumat LB9501 instrument, Bad Wildbach, Germany). The data were expressed as relative light units (RLU) per well of total cell protein.

\section{Intracellular expression and distribution of hTERTC27}

The C6 glioma cells were seeded at a density of $1 \times 10^{4}$ cells/well into $35 \mathrm{~mm}$ glass-bottom culture dishes (NEST, Wuxi, China) and cultured overnight. Then the cells were transfected with OX26/CTX-PL/pC27 solutions containing $4 \mu \mathrm{g}$ pC27. C6 cells were washed three times with PBS, fixed with $4 \%$ paraformaldehyde at $0,12,24,48 \mathrm{~h}$, respectively. Then the cells were washed with PBS and incubated with Lyso-Tracker Red (1:10000, $30 \mathrm{~min}$ ) and DAPI staining solution (5 $\mathrm{min}$ ) to visualize the lysosomes and nuclei, respectively. The prepared cells were observed using laser scanning confocal microscope (Carl Zeiss LSM700, Jena, Germany).

\section{In vitro effects on $\mathrm{C} 6$ cells of the modified and unmodified $\mathrm{PL} / \mathrm{pC} 27$ complexes}

The C6 glioma cells were transfected with OX26/CTX$\mathrm{PL} / \mathrm{pC} 27$ complexes loading with a series of weights of pC27 $(0.1 \mu \mathrm{g}, 0.2 \mu \mathrm{g}, 0.4 \mu \mathrm{g}, 0.8 \mu \mathrm{g}, 1.2 \mu \mathrm{g}, 1.6 \mu \mathrm{g})$ in 96-well culture plates. After the cells were cultured in the complete DMEM culture medium for $48 \mathrm{~h}$, cytotoxicity was performed using CCK-8 Kit. The cytotoxicity of PL/pC27, OX26-PL/pC27 and OX26/CTX-PL/pC27 containing $0.2 \mu \mathrm{g}$ pC27 was also assessed by CCK- 8 Kit. Each experiment was repeated for three times.

\section{Western blotting analysis}

The C6 glioma cells were transfected with OX26/CTXPL/pEGFP, PL/pC27, OX26-PL/pC27 and OX26/CTX$\mathrm{PL} / \mathrm{pC} 27$ complexes containing $4 \mu \mathrm{g}$ pDNA in 6-well plates. After the cells were incubated with complete culture medium for $48 \mathrm{~h}$ and total protein was extracted. Western blotting analysis was conducted as previously described [16]. Briefly, protein samples $(20 \mu \mathrm{g})$ were separated using SDS-PAGE and transferred onto polyvinylidene difluoride (PVDF) membrane. The membrane was incubated at room temperature for 1 hour in a blocking buffer ( $5 \%$ low fat milk), and was then incubated with a rabbit primary antibody (1:1000 dilution) against the hTERTC27. Secondary antibody, horseradish peroxidase
(HRP)-conjugated anti-rabbit IgG, was used to amplify the signal. The blots were developed using chemiluminescence system (New Life Science Products, Boston, MA, USA) and the results were photo-documented.

\section{In Vitro BBB model}

The BBB model was established using BMVECs as described previously [50]. Briefly, $2 \%$ gelatin was precoated on 12-well cell culture inserts (polyethylene terephtalate membrane, $3 \mu \mathrm{m}$ pore size, Millipore, Billerica, USA) for $30 \mathrm{~min}$. Then BMVECs were seeded into the inserts at a density of $7.5 \times 10^{4}$ cells/insert on day 1 . The culture mediums were changed every other day. $4 \mathrm{~h}$ permeation assay was conducted and transendothelial electrical resistance (TEER) values of the $\mathrm{BBB}$ were measured with the TEER instrument (Word Precision Instruments, Sarasota, FL, USA) on day 5. Only the BBB models with no medium permeation in $4 \mathrm{~h}$ and the TEER value over $250 \Omega \mathrm{cm}^{2}$ were included for experiments.

\section{Transport across the BBB and competition assay}

Lipoplexes, including PL/pC27, OX26-PL/pC27 and OX26/CTX-PL/pC27, in which pC27 was labeled by YOYO-1 [51], were added into the corresponding inserts at the plasmid concentration of $50 \mu \mathrm{g} / \mathrm{mL}$. For the competition assay, excessive amount of OX26 (100 $\mu \mathrm{g})$ was added into the inserts in advance for $30 \mathrm{~min}$, and then cells were treated with $\mathrm{PL} / \mathrm{pC} 27, \mathrm{OX} 26-\mathrm{PL} / \mathrm{pC} 27$ and OX26/CTX-PL/pC27. A volume of $400 \mu \mathrm{l}$ sample was taken from the acceptor compartments at $1,2,3,4 \mathrm{~h}$, and $400 \mu \mathrm{l}$ fresh medium was added immediately after each sampling. The effects of all lipoplexes on BBB integrity were monitored by measuring TEER values during the experiment. The $\mathrm{BBB}$ transport ratios of $\mathrm{pC} 27$ were determined by RF-5301PC fluorospectrophotometry (Shimadzu, Japan) with the excitation and emission wavelength at 491 and $509 \mathrm{~nm}$, respectively.

\section{Dual-targeting effects in vitro}

A BMVECs/C6 cells co-culture model was established as previously reported [41]. The BBB model was established and then the inserts were transferred to another 12-well plate where C6 cells had been cultured for 1 day. Lipoplexes, including $\mathrm{PL} / \mathrm{pC} 27, \mathrm{OX} 26-\mathrm{PL} / \mathrm{pC} 27$ and OX26/ CTX-PL/pC27, were added into the inserts of the BBB models at the plasmid concentration of $50 \mu \mathrm{g} / \mathrm{mL}$ for $4 \mathrm{~h}$, respectively, and then inserts were removed. After another $48 \mathrm{~h}$, the survival percentage of C6 glioma cells in the basolateral compartment was determined by SRB stainig assay.

\section{Dual-targeting effects and survival monitoring in vivo}

Rat orthotopic glioma model was established as previously described [16]. Briefly, male Wistar rats (250-280 g) were 
anesthetized with $10 \%$ chloral hydrate $(4 \mathrm{ml} / \mathrm{kg})$ and fixed in a stereotactic apparatus (Huaibei Zhenghua Instruments Co., Anhui, China). C6 glioma cells $\left(1 \times 10^{6}\right.$ cells suspended in $10 \mu \mathrm{l} \mathrm{PBS}$ ) were stereotactically implanted into the right caudate nucleus $(3 \mathrm{~mm}$ lateral and $1 \mathrm{~mm}$ anterior to the bregma, $5 \mathrm{~mm}$ of depth) with a Hamilton syringe (Shanghai Libao Instruments Co., Shanghai, China).

At day 3 after the implantation, the rats were divided into five groups (15 rats per group). Rats in blank control group were administered with PBS. Rats in the other 4 groups were treated with OX26/CTX-PL/pEGFP, PL/ pC27, OX26-PL/pC27 and OX26/CTX-PL/pC27complexes via the tail vein at a dose of $40 \mu \mathrm{g}$ pDNA per rat, respectively. Administration was made every 3 days with total 5 doses per rat. At day 18, six rats of each group were sacrificed for measuring the tumor size. The tumor volume was calculated by summing up the crosssectional areas using the formula: Volume $=a^{2} \times b \times \pi / 6$ ( $a$ and $b$ represent the width and length of the tumor). The rest of rats were used for monitoring the survival time, which was analyzed by the Kaplan-Meier survival curve.

\section{Histopathology and immunohistochemistry (IHC) study}

Rat brains were collected and stored in $4 \%$ paraformaldehyde. The sections were cut at $3 \sim 5 \mathrm{~mm}$ thick from paraffin-embedded brain tissue. After deparaffinization, sections were stained with haematoxylin and eosin (HE). IHC assay was performed using a standard two-step technique as demonstrated previously [52]. Briefly, after antigen retrieval was carried out by 4 minutes' high pressure method in Tris/EDTA buffer solution ( $\mathrm{pH}$ 9.0), the sections were incubated with $10 \%$ normal goat serum at room temperature for $10 \mathrm{~min}$ to reduce nonspecific reaction. Subsequently, the sections were incubated with anti-Telomerase reverse transcriptase antibody (1:100) overnight at $4^{\circ} \mathrm{C}$. The goat anti-rabbit $\operatorname{IgG}$ antibody-HRP polymer (ZSGB-BIO, Beijing, China) was used as a secondary link to DAB chromogen. Finally, the sections were counterstained with Mayer's hematoxylin. For the evaluation of hTERTC27 IHC staining, a semi-quantitative scoring method was used [53]. The staining intensity was scored as weak $(1+)$, moderate $(2+)$, and strong (3+). The number of positive staining cells were evaluated as follows: $0 \%(0),<10 \%(1)$, $10 \sim 50 \%$ (2), $51 \sim 80 \%$ (3); $>80 \%$ (4). The staining index (scores $0 \sim 12$ ) for each case was obtained by multiplying the values of the two parameters (percentage of the positive cells and predominant intensity).

\section{Statistics analysis}

Data were presented as mean \pm standard deviation (SD). One-way analysis of variance (ANOVA) was used to determine significance among groups following the Bonferroni's post-test. $\mathrm{p}<0.05$ was considered to be significant.

\section{Additional files}

Additional file 1: Figure S1. The effect of the weight ratio of DC-chol and pEGFP (A) or pC27 (B) on the particle size and zeta potential of PL/ pDNA complexes.

Additional file 2: Table S1. The particle size, PDI and zeta potential of the PL/pDNA complexes $(n=3)$.

Additional file 3: Figure S2. The TEM images of OX26/CTX-PL/pC27. Scale bar represents $100 \mathrm{~nm}$.

Additional file 4: Table S2. Encapsulation efficiency (EE) for the PL/ pDNA complexes $(n=3)$.

Additional file 5: Figure S3. The cell viability of the HEK293T and C6 cells after incubation with PL/pEGFP, OX26-PL/pEGFP and OX26/CTX-PL/ pEGFP complexes at $0.1,0.2,0.4,0.8,1.2,1.6 \mu \mathrm{g}$ of plasmid weights, respectively. (A) HEK293T cells, (B) C6 glioma cells.

Additional file 6: Figure S4. Fluorescent microscopy images of HEK293T cells, C6 and F98 gioma cells after transfection of Lipo2000/ pEGFP, PL/pEGFP, OX26-PL/pEGFP and OX26/CTX-PL/pEGFP complexes containing $1 \mu \mathrm{g}$ pIRES2-EGFP.

Additional file 7: Figure S5. Transfection efficiency of PL/pGL3-luc, OX26-PL/pGL3-luc and OX26/CTX-PL/pGL3-luc complexes containing $0.5 \mu \mathrm{g}, 1 \mu \mathrm{g}, 2 \mu \mathrm{g}$ pGL3-luc in (A) HEK293T, (B) C6 glioma cells, and (C) F98 glioma cells. The RLU value is given on the $Y$-axis and data are expressed as mean \pm SD $(n=3)$.

Additional file 8: Figure S6. Confocal images of C6 cells after incubation with OX26/CTX-PL/pC27 for 0 h, 12 h, 24 h and 48 h. Blue (DAPI), Red (Lyso-Tracker Red) and Green (EGFP) represent nuclei, lysosomes and hTERTC27 expression, respectively.

Additional file 9: Figure S7. hTERTC27 distribution in rat brains removed from (A) PBS control group; (B) PL/pC27 group; (C) OX26-PL/ pC27 group; (D) OX26/CTX-PL/pC27 group.

\section{Abbreviations}

ATCC: American Type Culture Collection; BBB: Blood-brain barrier; BMVECs: Brain microvascular endothelial cells; CCK-8: Cell counting kit-8; CTX: Chlorotoxin; EGFP: Enhanced green fluorescence protein; EPR: Enhanced permeability and retention; GBM: Glioblastoma multiforme; HE: Haematoxylin and eosin; HEK 293T: Human embryonic kidney 293T; hTERT: Human telomerase reverse transcriptase; hTERTC27: $27 \mathrm{kDa}$ C-terminal polypeptide of hTERT; IES: Interendothelial cell slit; IHC: Immunohistochemistry; 2-IT: 2-Iminothiolane hydrochloride (Traut's reagent); Lipo2000: Lipofectamine ${ }^{\text {TM }}$ 2000 Reagent; MMP-2: Matrix metalloproteinase-2; MPS: Mononuclear phagocyte system; OX-26: Anti-transferrin receptor antibody; OX26/CTX-PL/ pC27: pC27-loaded PEGylated liposomes modified with OX26 and CTX; OX26/ CTX-PL/pEGFP: pEGFP-loaded PEGylated liposomes modified with OX26 and CTX; pC27: Plasmid IRES2-EGFP/hTERTC27; pEGFP: Plasmid IRES2-EGFP; PDI: Polydispersity index; PEG: Polyethyleneglycol; pGL3-luc: pGL3 Luciferase Reporter Vectors; PLs: PEGylated liposomes; S100-PC: Soybean phosphatidylcholine; TEER: Transendothelial electrical resistance; TEM: Transmission electron microscope; Tf: Transferrin; TfR: Transferrin receptor.

\section{Competing interests}

The authors declare that they have no competing interests.

\section{Authors' contributions}

PJY carried out the preparation and determination of pegylated liposomes, statistical analysis and drafted the manuscript; LH participated in the evaluation and statistical analysis of the transfection efficiency; SWQ participated in the BMVECs/C6 cells co-culture model, YL participated in the rat orthotopic glioma model; YJL participated in the cytotoxicty assay and western blotting analysis; X-PL participated in the luciferase reporter assay and intracellular expression of hTERTC27; DX participated in the IHC study 
and performed its statistical analysis; YP conceived of the study, participated in its coordination, drafted and revised the manuscript. All authors read and approved the final manuscript.

\section{Acknowledgements}

This work was supported by National Natural Science Foundation of China (30973479, 31070953 and 81272197, to Y.P), International Collaboration Program of Universities in Guangdong province (2012gjhz001 to Y.P) and Science \& Technology Planning Project of Guangdong province (2009B060700040, to Y.P).

\section{Author details}

${ }^{1}$ Department of Neurology, Sun Yat-sen Memorial Hospital, Sun Yat-sen University, NO.107, Yan Jiang Xi Road of Guangzhou, Guangzhou 510120, China. ${ }^{2}$ Key Laboratory of Malignant Tumor Gene Regulation and Target Therapy of Guangdong Higher Education Institutes, Sun Yat-sen University, Guangzhou 510120, China. ${ }^{3}$ State Key Laboratory of Oncology in South China, Cancer Center, Sun Yat-Sen University, NO.651, Dongfeng Road East, Guangzhou 510060, China.

Received: 18 January 2014 Accepted: 8 August 2014

Published: 13 August 2014

\section{References}

1. Ricard D, Idbaih A, Ducray F, Lahutte M, Hoang-Xuan K, Delattre JY: Primary brain tumours in adults. Lancet 2012, 379:1984-1996.

2. Louis DN, Ohgaki H, Wiestler OD, Cavenee WK, Burger PC, Jouvet A, Scheithauer BW, Kleihues P: The 2007 WHO classification of tumours of the central nervous system. Acta Neuropathol 2007, 114:97-109.

3. Pardridge WM: BBB-genomics: creating new openings for brain-drug targeting. Drug Discov Today 2001, 6:381-383.

4. Arko L, Katsyv I, Park GE, Luan WP, Park JK: Experimental approaches for the treatment of malignant gliomas. Pharmacol Ther 2010, 128:1-36.

5. Stupp R, Hegi ME, Mason WP, van den Bent MJ, Taphoorn MJ, Janzer RC, Ludwin SK, Allgeier A, Fisher B, Belanger K, Hau P, Brandes AA, Gijtenbeek J, Marosi C, Vecht CJ, Mokhtari K, Wesseling P, Villa S, Eisenhauer E, Gorlia T, Weller M, Lacombe D, Cairncross JG, Mirimanoff RO: Effects of radiotherapy with concomitant and adjuvant temozolomide versus radiotherapy alone on survival in glioblastoma in a randomised phase III study: 5-year analysis of the EORTC-NCIC trial. Lancet Oncol 2009, 10:459-466.

6. Huwyler J, Wu D, Pardridge WM: Brain drug delivery of small molecules using immunoliposomes. Proc Natl Acad Sci U S A 1996, 93:14164-14169.

7. Abu Lila AS, Ishida T, Kiwada H: Targeting anticancer drugs to tumor vasculature using cationic liposomes. Pharm Res 2010, 27:1171-1183.

8. Sapra P, Allen TM: Ligand-targeted liposomal anticancer drugs. Prog Lipid Res 2003, 42:439-462.

9. Hu Y, Xie J, Tong YW, Wang CH: Effect of PEG conformation and particle size on the cellular uptake efficiency of nanoparticles with the HepG2 cells. J Control Release 2007, 118:7-17.

10. Park JW, Hong K, Kirpotin DB, Colbern G, Shalaby R, Baselga J, Shao Y, Nielsen UB, Marks JD, Moore D, Papahadjopoulos D, Benz CC: Anti-HER2 immunoliposomes: enhanced efficacy attributable to targeted delivery. Clin Cancer Res 2002, 8:1172-1181.

11. Allen TM, Cullis PR: Drug delivery systems: entering the mainstream. Science 2004, 303:1818-1822.

12. Mukthavaram $R$, Jiang $P$, Saklecha R, Simberg D, Bharati IS, Nomura N, Chao Y, Pastorino S, Pingle SC, Fogal V, Wrasidlo W, Makale M, Kesari S: High-efficiency liposomal encapsulation of a tyrosine kinase inhibitor leads to improved in vivo toxicity and tumor response profile. Int $J$ Nanomedicine 2013, 8:3991-4006.

13. Shi N, Boado RJ, Pardridge WM: Receptor-mediated gene targeting to tissues in vivo following intravenous administration of pegylated immunoliposomes. Pharm Res 2001, 18:1091-1095.

14. Ying $X$, Wen H, Lu WL, Du J, Guo J, Tian W, Men Y, Zhang Y, Li RJ, Yang TY, Shang DW, Lou JN, Zhang LR, Zhang Q: Dual-targeting daunorubicin liposomes improve the therapeutic efficacy of brain glioma in animals. J Control Release 2010, 141:183-192.

15. Ren J, Shen S, Wang D, Xi Z, Guo L, Pang Z, Qian Y, Sun X, Jiang X: The targeted delivery of anticancer drugs to brain glioma by PEGylated oxidized multi-walled carbon nanotubes modified with angiopep- 2 . Biomaterials 2012, 33:3324-3333.
16. Liang B, He ML, Chan CY, Chen YC, Li XP, Li Y, Zheng D, Lin MC, Kung HF, Shuai XT, Peng Y: The use of folate-PEG-grafted-hybranched-PEI nonvira vector for the inhibition of glioma growth in the rat. Biomaterials 2009, 30:4014-4020

17. Shi N, Pardridge WM: Noninvasive gene targeting to the brain. Proc Natl Acad Sci U S A 2000, 97:7567-7572.

18. Zhang Y, Jeong Lee H, Boado RJ, Pardridge WM: Receptor-mediated delivery of an antisense gene to human brain cancer cells. J Gene Med 2002, 4:183-194

19. Pardridge WM, Buciak JL, Friden PM: Selective transport of an anti-transferrin receptor antibody through the blood-brain barrier in vivo. $J$ Pharmacol Exp Ther 1991, 259:66-70.

20. Jefferies WA, Brandon MR, Hunt SV, Williams AF, Gatter KC, Mason DY: Transferrin receptor on endothelium of brain capillaries. Nature 1984, 312:162-163.

21. Wu D, Song BW, Vinters HV, Pardridge WM: Pharmacokinetics and brain uptake of biotinylated basic fibroblast growth factor conjugated to a blood-brain barrier drug delivery system. J Drug Target 2002, 10:239-245

22. Yoon DJ, Chu DS, Ng CW, Pham EA, Mason AB, Hudson DM, Smith VC, MacGillivray RT, Kamei DT: Genetically engineering transferrin to improve its in vitro ability to deliver cytotoxins. J Control Release 2009, 133:178-184.

23. Deshane J, Garner CC, Sontheimer H: Chlorotoxin inhibits glioma cell invasion via matrix metalloproteinase-2. J Biol Chem 2003, 278:4135-4144.

24. Lyons SA, O'Neal J, Sontheimer H: Chlorotoxin, a scorpion-derived peptide, specifically binds to gliomas and tumors of neuroectodermal origin. Glia 2002, 39:162-173.

25. Veiseh M, Gabikian P, Bahrami SB, Veiseh O, Zhang M, Hackman RC, Ravanpay AC, Stroud MR, Kusuma Y, Hansen SJ, Kwok D, Munoz NM, Sze RW, Grady WM, Greenberg NM, Ellenbogen RG, Olson JM: Tumor paint: a chlorotoxin:Cy5.5 bioconjugate for intraoperative visualization of cancer foci. Cancer Res 2007, 67:6882-6888

26. Sun C, Veiseh O, Gunn J, Fang C, Hansen S, Lee D, Sze R, Ellenbogen RG, Olson J, Zhang M: In vivo MRI detection of gliomas by chlorotoxin-conjugated superparamagnetic nanoprobes. Small 2008, 4:372-379.

27. Veiseh O, Kievit FM, Gunn JW, Ratner BD, Zhang M: A ligand-mediated nanovector for targeted gene delivery and transfection in cancer cells. Biomaterials 2009, 30:649-657.

28. Huang J, Lin MC, Bai YX, Jing DD, Wong BC, Han SW, Lin J, Xu B, Huang CF, Kung HF: Ectopic expression of a $\mathrm{COOH}$-terminal fragment of the human telomerase reverse transcriptase leads to telomere dysfunction and reduction of growth and tumorigenicity in HeLa cells. Cancer Res 2002, 62:3226-3232

29. Shay JW, Zou Y, Hiyama E, Wright WE: Telomerase and cancer. Hum Mol Genet 2001, 10:677-685.

30. Huo LF, Tang JW, Huang JJ, Huang PT, Huang CF, Kung HF, Lin MC: Cancer immunotherapy targeting the telomerase reverse transcriptase. Cell Mol Immunol 2006, 3:1-11.

31. Pardridge WM: Blood-brain barrier delivery. Drug Discov Today 2007, 12:54-61.

32. Gao JQ, Lv Q, Li LM, Tang XJ, Li FZ, Hu YL, Han M: Glioma targeting and blood-brain barrier penetration by dual-targeting doxorubincin liposomes. Biomaterials 2013, 34:5628-5639.

33. Zhang P, Hu L, Yin Q, Zhang Z, Feng L, Li Y: Transferrin-conjugated polyphosphoester hybrid micelle loading paclitaxel for brain-targeting delivery: synthesis, preparation and in vivo evaluation. $J$ Control Release 2012, 159:429-434

34. Shao K, Wu J, Chen Z, Huang S, Li J, Ye L, Lou J, Zhu L, Jiang C: A brain-vectored angiopep-2 based polymeric micelles for the treatment of intracranial fungal infection. Biomaterials 2012, 33:6898-6907.

35. Kaur IP, Bhandari R, Bhandari S, Kakkar V: Potential of solid lipid nanoparticles in brain targeting. J Control Release 2008, 127:97-109.

36. Qin Y, Chen H, Yuan W, Kuai R, Zhang Q, Xie F, Zhang L, Zhang Z, Liu J, He Q: Liposome formulated with TAT-modified cholesterol for enhancing the brain delivery. Int J Pharm 2011, 419:85-95.

37. Li SD, Huang L: Pharmacokinetics and biodistribution of nanoparticles. Mol Pharm 2008, 5:496-504.

38. Simoes S, Filipe A, Faneca H, Mano M, Penacho N, Duzgunes N, de Lima MP: Cationic liposomes for gene delivery. Expert Opin Drug Deliv 2005, 2:237-254

39. Zhang JS, Liu F, Huang L: Implications of pharmacokinetic behavior of lipoplex for its inflammatory toxicity. Adv Drug Deliv Rev 2005, 57:689-698. 
40. Ulbrich $\mathrm{K}$, Hekmatara T, Herbert E, Kreuter J: Transferrin- and transferrinreceptor-antibody-modified nanoparticles enable drug delivery across the blood-brain barrier (BBB). Eur J Pharm Biopharm 2009, 71:251-256.

41. Du J, Lu WL, Ying X, Liu Y, Du P, Tian W, Men Y, Guo J, Zhang Y, Li RJ, Zhou J, Lou JN, Wang JC, Zhang X, Zhang Q: Dual-targeting topotecan liposomes modified with tamoxifen and wheat germ agglutinin significantly improve drug transport across the blood-brain barrier and survival of brain tumor-bearing animals. Mol Pharm 2009, 6:905-917.

42. Jain S, Mishra V, Singh P, Dubey PK, Saraf DK, Vyas SP: RGD-anchored magnetic liposomes for monocytes/neutrophils-mediated brain targeting. Int J Pharm 2003, 261:43-55.

43. Szoka F Jr, Papahadjopoulos D: Procedure for preparation of liposomes with large internal aqueous space and high capture by reverse-phase evaporation. Proc Natl Acad Sci U S A 1978, 75:4194-4198.

44. Yang S, Chen J, Zhao D, Han D, Chen X: Comparative study on preparative methods of DC-Chol/DOPE liposomes and formulation optimization by determining encapsulation efficiency. Int J Pharm 2012, 434:155-160.

45. Shi N, Zhang Y, Zhu C, Boado RJ, Pardridge WM: Brain-specific expression of an exogenous gene after i.v. administration. Proc Natl Acad Sci U S A 2001, 98:12754-12759.

46. Pang Z, Lu W, Gao H, Hu K, Chen J, Zhang C, Gao X, Jiang X, Zhu C: Preparation and brain delivery property of biodegradable polymersomes conjugated with OX26. J Control Release 2008, 128:120-127.

47. Jones $L$, Haugland RP, Singer VL: Development and characterization of the NanoOrange protein quantitation assay: a fluorescence-based assay of proteins in solution. Biotechniques 2003, 34:850-854. 856, 858 passim.

48. Xin H, Jiang X, Gu J, Sha X, Chen L, Law K, Chen Y, Wang X, Jiang Y, Fang X: Angiopep-conjugated poly(ethylene glycol)-co-poly(epsiloncaprolactone) nanoparticles as dual-targeting drug delivery system for brain glioma. Biomaterials 2011, 32:4293-4305.

49. Rivest V, Phivilay A, Julien C, Belanger S, Tremblay C, Emond V, Calon F: Novel liposomal formulation for targeted gene delivery. Pharm Res 2007, 24:981-990.

50. Li Y, He H, Jia X, Lu WL, Lou J, Wei Y: A dual-targeting nanocarrier based on poly(amidoamine) dendrimers conjugated with transferrin and tamoxifen for treating brain gliomas. Biomaterials 2012, 33:3899-3908.

51. Qian Y, Zha Y, Feng B, Pang Z, Zhang B, Sun X, Ren J, Zhang C, Shao X, Zhang Q, Jiang X: PEGylated poly(2-(dimethylamino) ethyl methacrylate)/ DNA polyplex micelles decorated with phage-displayed TGN peptide for brain-targeted gene delivery. Biomaterials 2013, 34:2117-2129.

52. Cai MY, Zhang B, He WP, Yang GF, Rao HL, Rao ZY, Wu QL, Guan XY, Kung $H F$, Zeng YX, Xie D: Decreased expression of PinX1 protein is correlated with tumor development and is a new independent poor prognostic factor in ovarian carcinoma. Cancer Sci 2010, 101:1543-1549.

53. Brustmann H: Immunohistochemical detection of human telomerase reverse transcriptase (hTERT) and c-kit in serous ovarian carcinoma: a clinicopathologic study. Gynecol Oncol 2005, 98:396-402.

doi:10.1186/1476-4598-13-191

Cite this article as: Yue et al:: OX26/CTX-conjugated PEGylated liposome as a dual-targeting gene delivery system for brain glioma. Molecular Cancer 2014 13:191.

\section{Submit your next manuscript to BioMed Central and take full advantage of:}

- Convenient online submission

- Thorough peer review

- No space constraints or color figure charges

- Immediate publication on acceptance

- Inclusion in PubMed, CAS, Scopus and Google Scholar

- Research which is freely available for redistribution 